\title{
Correspondence
}

\section{The article 'Sex, gender and gender identity' fails to adequately engage with the extant scientific literature}

The recent paper titled 'Sex, gender and gender identity: a re-evaluation of the evidence', which appeared as a Special Article in the BJPsych Bulletin, contains concerning misrepresentations of the scholarly literature. The article selectively cites sources to make claims that are contrary to the available literature and best practices, which strongly support access to social, legal and medical transition. Using a direct quote, the authors claim that a Royal College of Psychiatrists position statement includes 'placing barriers [to] medical transition' within the meaning of conversion therapy. However, the document actually says 'place barriers in the way of trans people who seek advice regarding medical and/or social transition'. ${ }^{1}$ Raising barriers to transition and raising barriers to people seeking advice are two different things altogether, and the elision misrepresents the Royal College of Psychiatrists' position statement. Substantively altering quotes in this way is contrary to ethical authorship practices and is difficult to explain. While I would agree that preventing transition is a form of conversion therapy, as expressed in a recent report by UN Independent Expert Victor Madrigal-Borloz, ${ }^{2}$ this is not what the cited position statement says.

Despite discussing these topics, the authors fail to cite available data on the prevalence of anti-trans conversion therapy in the UK ${ }^{3}$ fail to acknowledge strong methodological criticisms of studies suggesting that most transgender youth grow up to be cisgender, ${ }^{4,5}$ fail to refer to empirical evidence of the harmfulness of misgendering and deadnaming; ${ }^{6-9}$ fail to mention that youth referred to gender identity clinics are significantly similar to those in the past despite changes in gender ratios; ${ }^{10}$ fail to substantially engage with significant evidence of mental health benefits to transition by brushing it off as immaterial to youth; ${ }^{11}$ fail to refer to evidence demonstrating that trans youth can be trusted about who they are and do not plausibly transition out of internalised homophobia; ${ }^{12-15}$ and fail to refer to a wealth of data showing transition and gender affirmation to have an important positive impact on mental health. ${ }^{16-23}$ Many references used in the article in support of substantial and contentious points are of poor quality and include news reports, non-peer-reviewed blog posts and a Tumblr survey.

Scientific literature must meet a high standard for publication. The editorial and peer-review process is intended to screen for problems such as these, which gravely threaten the quality of published works and undermine the public's ability to rely on scholarly publication as an indicium of reliability. Providing competent care for transgender youth depends upon the integrity of the scientific process, of which publication is an important part. The past few years have seen a concerning rise in articles opposing gender-affirming care being published in scientific journals despite failing to engage with the available literature and, at times, being directly contradicted by it. Transgender communities deserve high-quality research and scientific publications.

Gender-affirmative care remains the leading approach to care for transgender youth and is well supported by empirical evidence, clinical experience and ethical reasoning. ${ }^{24,25}$

Contrary to what the article's authors imply, gender-affirmative care does not foreclose youth's futures. Quite the contrary. ${ }^{26}$ Attempts to unduly delay or prevent social, legal or medical transition among youth who desire them should be opposed. Children and adolescents deserve unconditional acceptance and love at all points in their lives, including in their gender.

Florence Ashley, University of Toronto, Canada. Email: f.ashley@mail. utoronto.ca

1 Royal College of Psychiatrists. Supporting Transgender and Gender-Diverse People: Position Statement (PSO2/18). Royal College of Psychiatrists, 2018.

2 Madrigal-Borloz V. Practices of So-Called "Conversion Therapy", A/HRC/ 44/53. 2020.

3 Government Equalities Office. National LGBT Survey: Research Report. UK Government Equalities Office, 2018. Available from: https://assets. publishing.service.gov.uk/government/uploads/system/uploads/attachment_ data/file/721704/LGBT-survey-research-report.pdf.

4 Temple Newhook J, Pyne J, Winters K, Feder S, Holmes C, Tosh J, et al. A critical commentary on follow-up studies and "desistance" theories about transgender and gender-nonconforming children. Int J Transgend 2018; 19(2): 212-24.

5 Winters K. The "80\% desistance" dictum: is it science? In Families in Transition: Parenting Gender Diverse Children, Adolescents, and Young Adults (eds Al Lev, AR Gottlieb): 88-101. Harrington Park Press, 2019.

6 McLemore KA. Experiences with misgendering: identity misclassification of transgender spectrum individuals. Self Identity 2015; 14(1), 51-74.

7 McLemore KA. A minority stress perspective on transgender individuals' experiences with misgendering. Stigma Health 2018, 3(1), 53-64.

8 Restar A, Jin H, Breslow A, Reisner SL, Mimiaga M, Cahill S, et al. Legal gender marker and name change is associated with lower negative emotional response to gender-based mistreatment and improve mental health outcomes among trans populations. SSM Popul Health 2020; 11: 100595.

9 Russell ST, Pollitt AM, Li G, Grossman AH. Chosen name use is linked to reduced depressive symptoms, suicidal ideation, and suicidal behavior among transgender youth. J Adolesc Health 2018; 63(4): 503-5.

10 Arnoldussen M, Steensma TD, Popma A, van der Miesen AIR, Twisk JWR, de Vries ALC. Re-evaluation of the Dutch approach: are recently referred transgender youth different compared to earlier referrals? Eur Child Adolesc Psychiatry 2020; 29(6): 803-11.

11 Center for the Study of Inequality. What does the Scholarly Research Say about the Effect of Gender Transition on Transgender Well-Being? Cornell University, 2018. Available from: https://whatweknow.inequality.cornell. edu/topics/lgbt-equality/\%20what-does-the-scholarly-research-say-aboutthe-well-being-of-transgender-people\%20/.

12 Ashley F. Homophobia, conversion therapy, and care models for trans youth: defending the gender-affirmative model. J LGBT Youth 2020; 17(4): 361-83.

13 Gülgöz S, Glazier JJ, Enright EA, Alonso DJ, Durwood LJ, Fast AA, et al. Similarity in transgender and cisgender children's gender development. Proc Natl Acad Sci USA 2019; 116(49): 24480-5.

14 Pullen Sansfaçon A, Medico D, Suerich-Gulick F, Temple Newhook J. " knew that I wasn't cis, I knew that, but I didn't know exactly": gender identity development, expression and affirmation in youth who access gender affirming medical care. Int J Transgender Health 2020; 21(3): 307-20.

15 Rae JR, Gülgöz S, Durwood L, DeMeules M, Lowe R, Lindquist G, et al. Predicting early-childhood gender transitions. Psychol Sci 2019; 30(5): 669-81.

16 Allen LR, Watson LB, Egan AM, Moser CN. Well-being and suicidality among transgender youth after gender-affirming hormones. Clin Pract Pediatr Psychol 2019, 7(3), 302-11. 
17 Blasdel G, Belkind U, Harris A, Radix A. Description and Outcomes of a Hormone Therapy Informed Consent Model for Minors [Poster]. 25th WPATH Symposium, Buenos Aires, Argentina, 2018.

18 Durwood L, McLaughlin KA, Olson KR. Mental health and self-worth in socially transitioned transgender youth. I Am Acad Child Adolesc Psychiatry 2017; 56(2): 116-23.e2.

19 Fontanari AMV, Vilanova F, Schneider MA, Chinazzo I, Soll BM, Schwarz K, et al. Gender affirmation is associated with transgender and gender nonbinary youth mental health improvement. LGBT Health 2020, 7(5), 237-47.

20 Hill DB, Menvielle E, Sica KM, Johnson A. An affirmative intervention for families with gender variant children: parental ratings of child mental health and gender. J Sex Marital Ther 2010; 36(1): 6-23.

21 Johnson KC, LeBlanc AJ, Sterzing PR, Deardorff J, Antin T, Bockting WO Trans adolescents' perceptions and experiences of their parents' supportive and rejecting behaviors. J Couns Psychol 2020; 67(2): 156-70.

22 Kuper LE, Stewart S, Preston S, Lau M, Lopez X. Body dissatisfaction and mental health outcomes of youth on gender-affirming hormone therapy. Pediatrics 2020; 145(4): e20193006.

23 Turban JL, King D, Carswell JM, Keuroghlian AS. Pubertal suppression for transgender youth and risk of suicidal ideation. Pediatrics 2020; 145 (2): e20191725.

24 Lopez X, Marinkovic M, Eimicke T, Rosenthal SM, Olshan JS. Statement on gender-affirmative approach to care from the pediatric endocrine society special interest group on transgender health. Curr Opin Pediatr 2017; 29(4): 475-80.

25 Telfer MM, Tollit MA, Pace CC, Pang KC. Australian Standards of Care and Treatment Guidelines for Trans and Gender Diverse Children and Adolescents, Version 1.1. The Royal Children's Hospital, 2018.

26 Ashley F. Thinking an ethics of gender exploration: against delaying transition for transgender and gender creative youth. Clin Child Psychol Psychiatry 2019; 24(2): 223-36.

\section{doi:10.1192/bjb.2021.77}

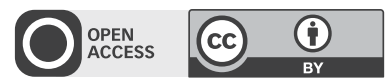

(c) The Author(s), 2021. Published by Cambridge University Press on behalf of the Royal College of Psychiatrists. This is an Open Access article, distributed under the terms of the Creative Commons Attribution licence (http://creativecommons.org/ licenses/by/4.0/), which permits unrestricted re-use, distribution, and reproduction in any medium, provided the original work is properly cited.

\section{Authors' reply}

Thank you for publishing our article ${ }^{1}$ and facilitating academic debate in this rapidly evolving area of healthcare. It is unsurprising to find disagreement over the interpretation of existing research, and we welcome this opportunity to respond to Ashley and review the many references supplied, including data published after our article was accepted. We happily address Ashley's points and respond to all individual references in Table 1 https://doi.org/10.6084/m9.figshare.13626380.v3.

We stated that the College sees the placement of barriers to seeking transition as a form of conversion therapy, and we shortened - but did not substantively change - the position statement quote. ${ }^{2}$ We believe it accurately represents the meaning, and indeed the same abbreviation was used within the body of the position statement itself. If we are wrong about the College's stance, and we agree there is a lack of specificity about barriers, others too may be confused. Given moves to criminalise conversion therapies, ${ }^{3}$ the College should clarify what constitutes unacceptable practice ${ }^{4}$ and be clear that provision of psychological interventions to address existing mental health needs before referral for cross-sex hormones, or surgery, would not constitute a barrier or conversion therapy. This is of particular importance since the recent UK judicial review, which found that young people are unlikely to be able to provide informed consent for early medical intervention.

We agree we used some non-peer-reviewed literature. It is well established that dissenting voices can go unheard by invested clinicians and reports of harm take much longer to recognise. ${ }^{5}$ In a word-constrained, broad-based discussion, we could not analyse all the existing literature about natural history, persistence of gender incongruence in youth, rising referrals, or the age and sex switches, though these have been covered elsewhere. ${ }^{6}$ Similarly, other authors have noted that gender dysphoria is a common step in the developmental pathway of same-sex attraction. ${ }^{7}$

Proponents of affirmative care often claim that medical transition is well studied, with academic consensus on effectiveness. In reality, the literature is fraught with study design problems, including convenience sampling, lack of controls, small sample sizes, short study lengths and high drop-out rates among participants. Most of the studies cited in Ashley's letter were of crosssectional observational design (Table 1) https://doi.org/10.6084/ m9.figshare.13626380.v3. These low quality studies are unable to demonstrate causality and are susceptible to confounders. An important example of the shortcomings of such convenience sampling is the 2020 paper by Turban et al, which claims to demonstrate lower suicidal ideation in adults who had been prescribed GnRHa in adolescence. ${ }^{8}$ There are a number of methodological shortcomings associated with this biased sampling, ${ }^{9}$ the most worrying being the authors' failure to recognise that this single positive finding is inevitable as prescribers would only have offered puberty blockers to adolescents with stable mental health. Those adolescents with severe psychological problems would not have been eligible. Suicidal ideation is almost certainly related to poor mental health (both past and present) in this group rather than any lack of puberty blockade. This same fact also renders any retrospective desire for treatment invalid. The authors' recommendation that 'this treatment [should] be made available to transgender adolescents who want it' is unsupportable.

Before-and-after studies and case-note reviews are similarly unreliable. Like first-hand accounts, they are mainly useful for raising, not answering, quantitative questions. Benefits will be bolstered by mutual belief systems, clinician charisma, powerful mood-altering drugs and body modifications, as well as the placebo effect. By their nature, these kinds of evidence are unconvincing to an ethical medical profession with a long history of causing harm. ${ }^{5}$

The problem of missing data distorts routinely quoted high levels of satisfaction and low regret rates in transgender healthcare. It is unknown whether large losses to follow-up in gender dysphoria research, often over $30 \%,{ }^{10}$ mask adverse effects, including death by suicide, cardiovascular disease or general morbidity associated with deteriorating mental and physical health. Thus, long-term cohort data, as well as appropriate randomised trials, are essential. ${ }^{11}$

Publication bias in this area can be demonstrated by a key 'positive' published study ${ }^{12}$ which was widely reported by media outlets. This population-based study initially reported a 'longitudinal association between gender-affirming surgery and reduced likelihood of mental health treatment' and declared that these findings 'lend support to the decision to provide gender-affirming surgeries to transgender individuals who seek them'. However, 